PSICOLOGÍA

IBEROAMERICANA
Psicología Iberoamericana ISSN: $1405-0943$

revista.psicologia@ibero.mx

Universidad Iberoamericana, Ciudad de México México

\title{
Reseña del libro. Handbook of positive youth development. Advancing research, policy and practice in the global contexts, Radosveta Dimitrova \& Nora Wiium (Springer, 2021), pp. 754
}

Salinas-Quiroz, Fernando

Reseña del libro. Handbook of positive youth development. Advancing research, policy and practice in the global contexts, Radosveta Dimitrova \& Nora Wiium (Springer, 2021), pp. 754

Psicología Iberoamericana, vol. 29, núm. 2, e292400, 2022

Universidad Iberoamericana, Ciudad de México, México

Disponible en: https://www.redalyc.org/articulo.oa?id=133967822003

DOl: https://doi.org/10.48102/pi.v29i2.400

Los autores/as conservan los derechos de autor y ceden a la revista el derecho de la primera publicación, con la obra registrada bajo la Licencia Creative Commons Atribución 4.0 Internacional.

Los autores/as conservan los derechos de autor y ceden a la revista el derecho de la primera publicación, con la obra registrada bajo la Licencia Creative Commons Atribución 4.0 Internacional.

\section{(c) (i)}

Esta obra está bajo una Licencia Creative Commons Atribución 4.0 Internacional. 
Reseñas de libros

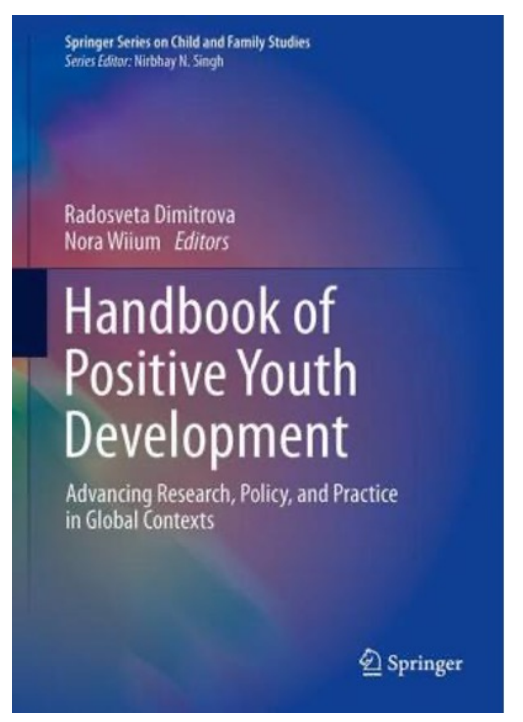

\section{Reseña del libro. Handbook of positive youth development. Advancing research, policy and practice in the global contexts, Radosveta Dimitrova \& Nora Wiium (Springer, 2021), pp. 754}

Book review. Handbook of Positive Youth Development. Advancing Research, Policy and Practice in the Global Contexts, Radosveta Dimitrova \& Nora Wiium (Springer, 2021), pp. 754

Fernando Salinas-Quiroz fernando.salinas@tutfs.edu Universidad Tufts, Estados Unidos iD https://orcid.org/0000-0002-1257-6379

Dimitrova Radosveta, Wiium Nora. Handbook of positive youth development. Advancing research, policy and practice in the global contexts. 2021. Suiza. Springer. 754pp..

978-3-030-70261-8

Psicología Iberoamericana, vol. 29, núm. 2, e292400, 2022

Universidad Iberoamericana, Ciudad de México, México

Recepción: 01 Junio 2021

Aprobación: 01 Agosto 2021

DOI: https://doi.org/10.48102/ pi.v29i2.400

Redalyc: https://www.redalyc.org/ articulo.oa?id=133967822003
Cuando acepté la invitación de Radosveta para realizar la reseña del Manual de Desarrollo Positivo de la Juventud: Avances de investigación, politicas y prácticas en contextos globales (Handbook of Positive Youth Development. Advancing Research and Practice in the Global Contexts), no sabía en qué me metía. Digo lo anterior, pues parte importante de mi encomienda no es solamente realizar una síntesis y un recorrido por cada apartado del libro, sino también resaltar aquello que considero único y especial de la obra. ¿Cómo respetar las limitaciones de espacio, sin ser superficial? ¿Cómo invitar a quienes me leen a que la adquieran sin hacer revelaciones cruciales y estropear su experiencia (o, como dirían las personas jóvenes, "sin spoilerearla")? Por último, ¿Cómo lograrlo con un volumen que es extraordinario y sobresaliente en su totalidad? En fin, ¡Haré mi mejor esfuerzo!

La primera característica que quiero resaltar del Manual editado por las doctoras Radosveta Dimitrova y Nora Wiium es su enfoque: se centra en las fortalezas -y no así en las debilidades o déficits-; se trata de una obra que subraya baluartes universalmente relevantes para el desarrollo humano, pero que también destaca la necesidad de contextualizar simulatáneamente las culturas y los contextos únicos en donde se desarrollan las juventudes ${ }^{[1]}$. 
Como si lo anterior no fuera imperativo y sumamente novedoso, se suma el hecho de que varias de las investigaciones se realizaron con grupos culturales subrepresentados -i.e., 22,083 personas jóvenes y adultas emergentes de 38 países-; de manera que investigadoras e investigadores del llamado "Sur Global” - mejor hablar de países en vías de desarrollo, pues yo veo a 'América Invertida' tal y como genialmente lo plasmó Joaquín Torres García- fungen como portavoces de juventudes distintas y diversas. Por medio de este proceso integrador, las y los autores de los distintos capítulos asumen las fortalezas de los individuos jóvenes, pero particularmente el compromiso de escuchar sus voces y comprender sus vidas, desafíos, necesidades y aspiraciones específicas, tomando distancia de discursos dominantes que conciben al desarrollo juvenil desde una perspectiva de riesgo, patologizante y basada exclusivamente en valores occidentales.

Dejando a un lado el tema de la representación, que no es poca cosa, la obra también abona al perfeccionamiento de aspectos metodológicos y de medición relacionados con el desarrollo positivo de las juventudes por medio estudios cuantitativos, cualitativos y mixtos, así como a la integración de esta línea de investigación con políticas públicas y prácticas ad hoc. El Manual está organizado en dos secciones que agrupan 37 capítulos. La primera, "Desarrollo Positivo de la Juventud en Contextos Globales" contiene 17 capítulos con nuevas conceptualizaciones, tal como el Modelo de las 7Cs, así como ejemplos de investigaciones realizadas en India, Indonesia, Pakistán, Malasia, China, Ghana, Colombia, Perú, México, Belice, Brasil, Albania, Kosovo, Macedonia, Serbia, Turquía, Italia, España, Islandia, Noruega, Australia, Nueva Zelanda, Bulgaria y Rumanía. La segunda, "Aplicaciones e intervenciones", cuenta con 18 capítulos sobre revisiones, aproximaciones e intervenciones innovadoras en contextos diversos en países como China, Colombia, Italia, Jordania, Kenia, Filipinas, Suecia, Tailandia, Jamaica, Sudáfrica, Eslovenia, Lituania , Finlandia, Noruega, Canadá, y Estados Unidos.

Con contribuciones únicas, muestras diversas y enfoques globales sobre investigación, políticas y prácticas, este Manual ofrece una colección completa e inclusiva de perspectivas no convencionales y contemporáneas sobre el desarrollo positivo de las juventudes a una amplia gama de personas que se dedican a las ciencias sociales; individuos que formulan políticas públicas; y, estudiantes y prácticantes de una variedad de disciplinas (psicología positiva, del desarrollo, transcultural, social y comunitaria, así como estudios sobre el bienestar, las niñeces y sus familias, personas adultas emergentes, educación, prevención, relaciones interculturales, antropología, sociología, metodología y consejería, por mencionar algunas).

El Manual de Desarrollo Positivo de la Juventud: Avances de investigación, políticas y prácticas en contextos globales no genera exclusivamente conocimiento, sino que también estimula a quienes formulamos políticas públicas, nos dedicamos a la investigación, o al trabajo directo con personas jóvenes y adultas emergentes a seguir comprometiéndonos con ellas en sus respectivas culturas y sociedades. 
Este volumen constituye un proyecto o plan colectivo sobre cómo el estudio del desarrollo positivo de las juventudes, basado en las culturas y los contextos locales, puede convertirse en la base de sociedades más justas y sostenibles.

\section{Notas}

1 Evito utilizar el término adolescencia, pues solemos asociarlo con lo tormentoso/problemático y con fallas en el control de impulsos; además, me parece que remite a una forma de ser joven, en la que la meta suele ser "dejar el nido", estudiar una carrera universitaria, y guiarse por valores individualistas y de mercado. En congruencia con este punto, emplear el plural permite explorar varias posibilidades de ser joven. 